\title{
Heterothermy as the Norm, Homeothermy as the Exception: Variable Torpor Patterns in the South American Marsupial Monito del Monte (Dromiciops gliroides)
}

\author{
Roberto F. Nespolo 1,2,3*, Carlos Mejías ${ }^{1}$, Angelo Espinoza ${ }^{1}$, Julián Quintero-Galvis', \\ Enrico L. Rezende ${ }^{2}$, Francisco E. Fontúrbel ${ }^{4}$ and Francisco Bozinovic ${ }^{2}$
}

${ }^{1} /$ nstituto de Ciencias Ambientales y Evolutivas, Universidad Austral de Chile, Valdivia, Chile, ${ }^{2}$ Center of Applied Ecology and Sustainability (CAPES), Departamento de Ecología Facultad de Ciencias Biológicas, Pontificia Universidad Católica de Chile,

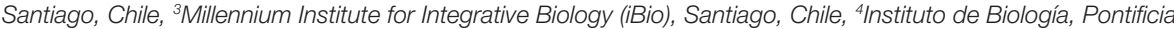
Universidad Católica de Valparaíso, Valparaíso, Chile

\section{OPEN ACCESS}

Edited by: Alessandro Silvani, University of Bologna, Italy

Reviewed by: Fritz Geiser, University of New England, Australia Lin Zhang, Hubei University of Chinese Medicine,

${ }^{*}$ Correspondence:

Roberto F. Nespolo robertonespolorossi@gmail.com

Specialty section:

This article was submitted to Integrative Physiology, a section of the journal Frontiers in Physiology

Received: 18 March 2021 Accepted: 11 June 2021 Published: 12 July 2021

Citation:

Nespolo RF, Mejías C, Espinoza A, Quintero-Galvis J, Rezende EL, Fontúrbel FE and Bozinovic F (2021)

Heterothermy as the Norm, Homeothermy as the Exception: Variable Torpor Patterns in the South

American Marsupial Monito del Monte (Dromiciops gliroides).

Front. Physiol. 12:682394.

doi: 10.3389/fphys.2021.682394
Hibernation (i.e., multiday torpor) is considered an adaptive strategy of mammals to face seasonal environmental challenges such as food, cold, and/or water shortage. It has been considered functionally different from daily torpor, a physiological strategy to cope with unpredictable environments. However, recent studies have shown large variability in patterns of hibernation and daily torpor ("heterothermic responses"), especially in species from tropical and subtropical regions. The arboreal marsupial "monito del monte" (Dromiciops gliroides) is the last living representative of the order Microbiotheria and is known to express both short torpor episodes and also multiday torpor depending on environmental conditions. However, only limited laboratory experiments have documented these patterns in D. gliroides. Here, we combined laboratory and field experiments to characterize the heterothermic responses in this marsupial at extreme temperatures. We used intraperitoneal data loggers and simultaneous measurement of ambient and body temperatures ( $T_{\mathrm{A}}$ and $T_{\mathrm{B}}$, respectively) for analyzing variations in the thermal differential, in active and torpid animals. We also explored how this differential was affected by environmental variables ( $T_{\mathrm{A}}$, natural photoperiod changes, food availability, and body mass changes), using mixed-effects generalized linear models. Our results suggest that: (1) individuals express short bouts of torpor, independently of $T_{\mathrm{A}}$ and even during the reproductive period; (2) seasonal torpor also occurs in $D$. gliroides, with a maximum bout duration of 5 days and a mean defended $T_{\mathrm{B}}$ of $3.6 \pm 0.9^{\circ} \mathrm{C}$ (one individual controlled $T_{\mathrm{B}}$ at $0.09^{\circ} \mathrm{C}$, at sub-freezing $T_{\mathrm{A}}$ ); (3) the best model explaining torpor occurrence (Akaike information criteria weight = 0.59) discarded all predictor variables except for photoperiod and a photoperiod by food interaction. Altogether, these results confirm that this marsupial expresses a dynamic form of torpor that progresses from short torpor to hibernation as daylength shortens. These data add to a growing body of evidence characterizing tropical and 


\section{sub-tropical heterothermy as a form of opportunistic torpor, expressed as daily or seasonal torpor depending on environmental conditions.}

Keywords: Dromiciops gliroides, hibernation, Microbiotheria, passive cooling, heterothermia, torpor, non-Holarctic heterotherms

\section{INTRODUCTION}

Many endotherms (i.e., birds and mammals) express transient periods of metabolic depression (known as "torpor" or "heterothermy") as adaptations to seasonal or unpredictable changes in environmental productivity (Schmidt-Nielsen, 1979; Ruf and Geiser, 2015). When torpid, animal maintenance costs fall to a fraction of the resting metabolic rate (RMR), providing significant energy savings (up to 95\%, according to Geiser, 2020). Thus, this should be the "logical" solution for animals that cannot migrate to better environments during seasons of resource scarcity (Schmidt-Nielsen, 1979). The metabolic depression during torpor can be profound, with body temperatures $\left(T_{\mathrm{B}}\right)$ approaching ambient temperature $\left(T_{\mathrm{A}}\right)$ and torpor bout duration of several days or weeks. This has been classically referred as "hibernation" or "seasonal torpor" (Geiser and Heldmaier, 1995; Heldmaier et al., 2004; Geiser, 2020; Nowack et al., 2020). Nevertheless, several species also express short episodes of heterothermy, lasting a few hours or a day, called "daily torpor".

In the southern hemisphere, it was estimated that $43 \%$ of the Australian mammal species exhibit some form of heterothermy (Geiser and Körtner, 2010), showing a large physiological diversity, ranging from the long hibernation of echidnas (7 months) to the short torpor bouts of Dasyurid marsupials and bats (Geiser and Körtner, 2010). In these animals, the metabolic reduction of torpor ranges from $29.5 \%$ of basal metabolic rate in daily heterotherms $\left(T_{\mathrm{B}}\right.$ reductions of $\left.\sim 20^{\circ} \mathrm{C}\right)$ to $5.1 \%$ in hibernators $\left(T_{\mathrm{B}}\right.$ reductions of $\sim 30^{\circ} \mathrm{C}$, see Geiser and Ruf, 1995). Interestingly, in hibernators even short torpor bouts elicit these important metabolic reductions. On the other hand, African heterotherms include Madagascar tenrecs (Echinops telfari), displaying seasonal torpor (Lovegrove and Genin, 2008), and elephant shrews (Elephantulus spp.) expressing characteristics of daily torpor (bout duration) and hibernation (metabolic reduction; Lovegrove et al., 2001). Cheirogaleidae lemurs (Ortmann et al., 1997) express daily torpor even at "warm" temperatures, and the mouse lemur (Microcebus murinus) showing flexible heterothermic phenotypes (Schmid and Ganzhorn, 2009).

Although torpor has been described on a few South American species of birds and mammals (hummingbirds: Carpenter, 1974; Wolf et al., 2020; bats: Bozinovic et al., 1985; rodents: Bozinovic and Marquet, 1991; didelphid marsupials: Bozinovic et al., 2007), multiday torpor was only described in the Patagonian opossum (Lestodelphys halli; which can attain a torpor duration of up to $42.5 \mathrm{~h}$, see Geiser and Martin, 2013), and in the Microbiotheriid "monito del monte" (Dromiciops gliroides) known to express torpor bouts of up to $120 \mathrm{~h}$ (Bozinovic et al., 2004). However, the absence of systematic studies characterizing naturally occurring torpor in South American endotherms is notable, especially from the Neotropical region.

Here, we analyzed the natural heterothermic patterns of D. gliroides ("monitos," hereafter), which have remained unclear since the first description by Bozinovic et al. (2004), mainly because all evidence on this species come from short-term laboratory trials (Bozinovic et al., 2004; Nespolo et al., 2010; Franco et al., 2017). For example, in a recent review, monitos are described as hibernating "apparently mainly in winter" (Geiser, 2020, p. 9). However, the same year other authors classified monitos as opportunistic heterotherms that enter torpor under long photoperiod and relatively warm temperatures, even when food is available (Nowack et al., 2020, p. 17). Thus, to clarify this information and explore how this marsupial performs at extreme temperatures, we performed this study, combining laboratory and field experiments. We believe that this is important as, besides being one of the few South American mammals described as hibernator, monitos are a paradigmatic species (see below).

Today, living South American marsupials represent nearly $10 \%$ of the mammalian fauna of South America and comprise about 100 species grouped in the orders Didelphimorphia, Paucituberculata, and the relict order Microbiotheria, which is represented by the sole living species D. gliroides (Goin et al., 2016). Microbiotheria was a marsupial order that comprised at least 14 species that dominated southern South America in the Eocene-Miocene, encompassing a wide geographic range that extended from present day Bolivia to Antarctica (Hershkovitz, 1999; Goin and Abello, 2013; Goin et al., 2016). Abundant fossil evidence, as well as current Dromiciops biology, suggests that Microbiotheriids were intimately associated with the neotropical temperate forests, forming the so-called Microbiothere-Chusquea-Nothofagus association (Hershkovitz, 1999). Also, Microbiotheria are known to be the sister group of Australidelphia (Australian marsupials), which colonized Australia through an Antarctic bridge during the Cretaceous (Nilsson et al., 2010; Mitchell et al., 2014). Then, Dromiciops could be considered as the Australidelphian ancestral model, which evolved and diversified into forms as diverse as koalas, wallabies, and Tasmanian devils (Nilsson et al., 2010; Mitchell et al., 2014; Goin et al., 2016).

Monitos are presently distributed over a broad geographic range (ca. $900 \mathrm{~km}$ north to south), including Andean forests where freezing temperatures are common in winter (e.g., Altos de Lircay and Futaleufú, see Oda et al., 2019; Mejias et al., 2021). In these locations, monitos probably hibernate at temperatures close to zero. But also, monitos are present in populations where summer temperatures surpass $30^{\circ} \mathrm{C}$, in the northern edge of the range $\left(=35^{\circ} \mathrm{S}\right.$, see Uribe et al., 2017). In the laboratory, monitos trigger their heterothermic state primarily 
when fasted, and torpor episodes are deeper and longer under cold conditions (Nespolo et al., 2010, 2021). The transition from homeothermy to heterothermy in the monitos is characterized by passive cooling after a sudden reduction in metabolic rate, which takes about $5-6 \mathrm{~h}$ depending on $T_{\mathrm{A}}$ (Cortes et al., 2014). It is unknown if monitos defend a minimum $T_{\mathrm{B}}$ and thermoregulate in torpor and if they arouse at some critical $T_{\mathrm{A}}$.

The control of $T_{\mathrm{B}}$ during heterothermia ("torpor thermoregulation," hereafter) was first described by (Hainsworth and Wolf, 1970), in the hummingbird Eulampis jugularis, and is represented in the metabolic curve by a negative slope line running below (and parallel) to the euthermic metabolic curve (Figure 1; Rezende and Bacigalupe, 2015).

Then, below a certain critical $T_{\mathrm{A}}\left(=T_{\mathrm{Bmin}}\right)$, the torpid animal stops passive cooling (represented by the dotted line in Figure 1) and begins metabolic heat production, maintaining constant $T_{\mathrm{B}}$. Torpor thermoregulation has been subsequently described in several species of mammals (Geiser and Baudinette, 1987; Richter et al., 2015) and birds (Hiebert, 1990; Wolf et al., 2020).

In this study we analyzed a suite of torpor thermoregulatory patterns in $D$. gliroides, by recording $T_{\mathrm{A}}$ and $T_{\mathrm{B}}$ using miniature data loggers in individuals under field and laboratory conditions. In addition, we used the $T_{\mathrm{B}}-T_{\mathrm{A}}$ thermal differential to estimate the environmental factors that best explain the field occurrence of torpor. We hypothesized that: (1) D. gliroides is an opportunistic hibernator that could express short and multiday torpor depending on environmental conditions; (2) short torpor shifts into multiday torpor as the cold season progresses, primarily induced by shortening daylength and reduced food availability, and (3) D. gliroides has a critical torpor temperature slightly higher than zero degrees, thereby thermoregulating to control its $T_{\mathrm{B}}$ above freezing temperature.

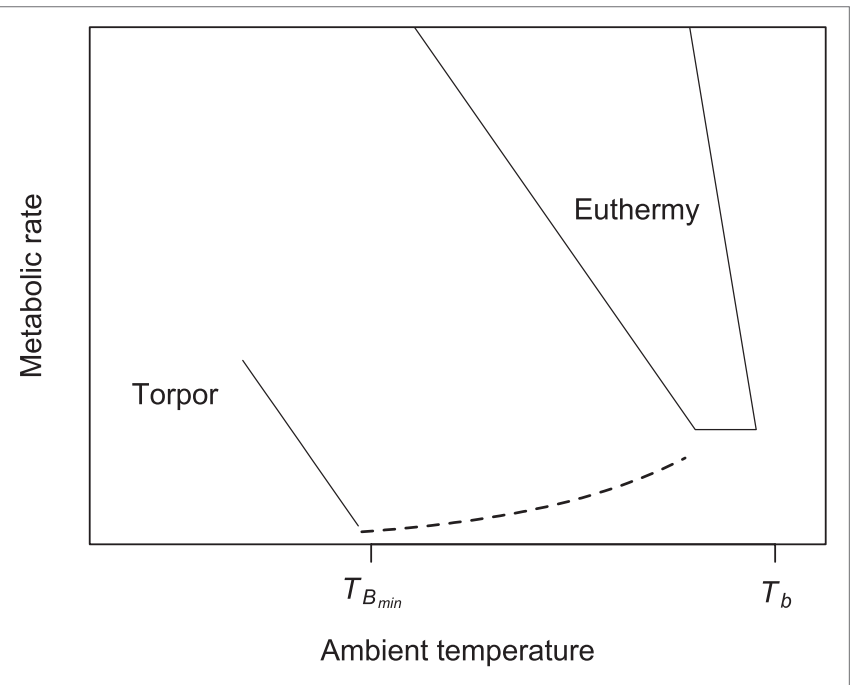

FIGURE 1 | A thermoregulatory polygon of a hibernator, showing the metabolic curve of torpor and the critical body temperature where animals start thermoregulating in torpor ( $T_{\mathrm{Bmin}}$; see text for details, modified from Rezende and Bacigalupe, 2015).

\section{MATERIALS AND METHODS}

\section{Animals}

All procedures presented in this study were approved by the Chilean Agriculture and Livestock Bureau (SAG; permits No $4371 / 2019$ and 3393/2019) and by the Bioethics Committee of the Austral University of Chile (resolution 313/2018 annex 2019). We performed the experiments in eight D. gliroides individuals $\left(M_{\mathrm{B}}\right.$ range: $26.1-54.8 \mathrm{~g}$, five females, three males) over 2 years. Animals were captured in San Martin Biological Station $\left(39^{\circ} 38^{\prime} 50.71^{\prime} \mathrm{S} 73^{\circ} 11^{\prime} 46.43^{\prime} \mathrm{O}\right)$ in February 2019. No animal was harmed in these procedures, the data loggers were safely removed, and all animals were released at the place of capture after finishing the study. We followed the guidelines of the American Society of Mammalogists for the use of wild mammals in research (Gannon et al., 2007; Sikes et al., 2011). Since we only had four functional data loggers, experiments had to be done in different batches for reusing the devices.

We included data from 2019 where several individuals $(n=25)$ were captured in San Martin in February and maintained in enclosures, for another study. In one of the enclosures this year (with three males and two females), one of the females gave birth to two pups of approximately $4 \mathrm{~mm}$, which were discovered on December 10 (approximate age: 2 weeks; MuñozPedreros et al., 2005). 1 week later (December 17, 12 am, $T_{\mathrm{A}}=25^{\circ} \mathrm{C}$ ), we found the whole cluster of five animals torpid, including the female and the two pups (cloacal $T_{\mathrm{B}}=25.3 \pm 0.4^{\circ} \mathrm{C}$, mean $\pm \mathrm{SE}$; Figure 2).

We included these results in this paper, as it contributes to the idea that $D$. gliroides routinely perform torpor independently of the season and even during the reproductive period. We later released the female with the pups at the site of capture.

\section{Datalogger Deployment}

We surgically implanted body temperature $\left(T_{\mathrm{B}}\right)$ dataloggers (model DST nano, $1.3 \mathrm{~g}$, cylindric, $17 \mathrm{~mm}$ long, $6 \mathrm{~mm}$ diameter; Star Oddi, Iceland) into the abdomen (i.e., intraperitoneal) of four individuals in March 2019 (autumn) and removed them in November (spring). According to the manufacturer, the devices are calibrated at factory over a temperature range of $-10-50^{\circ} \mathrm{C}$. We calibrated the devices in a beaker with water at $40^{\circ} \mathrm{C}$ that was allowed to cool to room temperature $\left(10^{\circ} \mathrm{C}\right)$, with temperature records every $2 \mathrm{~min}$, using a laboratory thermometer (alcohol). The linear regression between water and logger temperature (20 points) was highly significant $\left(R^{2}=0.99, p=0.001\right)$. We set the dataloggers for hourly recordings during the first winter. The next winter, we reused them in other two animals for one-month ramp experiments designed to determine torpor patterns at a broad thermal range (see details in the "ramp experiment" section below). We removed dataloggers from these animals after 1 month of continuous measurements. For both implantation and removal, we used subcutaneous tramadol $5 \mathrm{mg} \mathrm{kg}$, plus inhalation anesthesia for induction (isoflurane in oxygen 5\%) and maintenance (isoflurane in oxygen $2.5 \%$ ). We then administered subcutaneous 


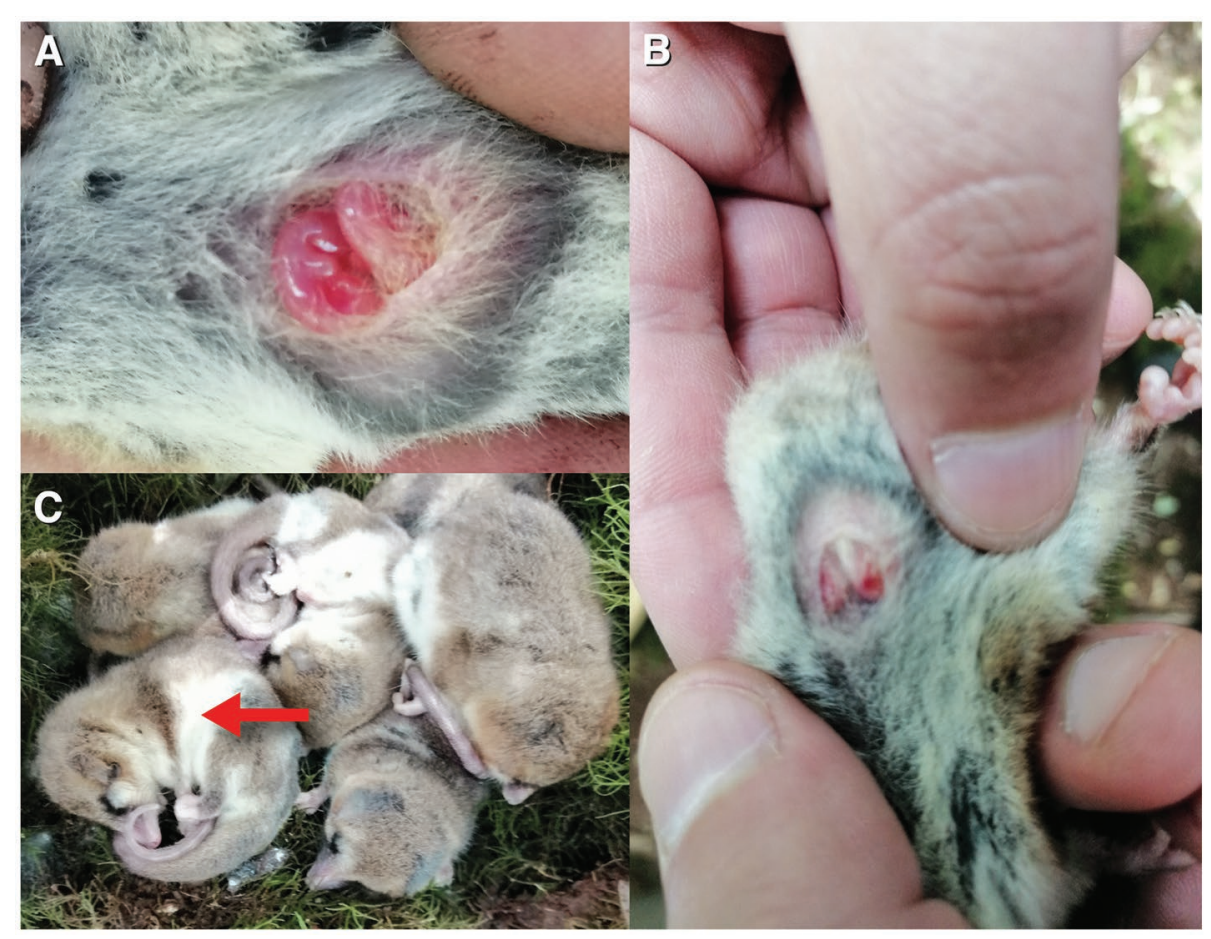

FIGURE 2 | (A) torpid pups ( $n=2$, approximate age: 3 weeks) found in a torpid female $\left(M_{\mathrm{B}}=25 \mathrm{~g}\right)$ on December 18,2020 , in the field, with $T_{\mathrm{A}}=25^{\circ} \mathrm{C}$ and $T_{\mathrm{B}}$ of the female $=25.1^{\circ} \mathrm{C}$. Pups were not moving. (B) shows another view, and (C) shows the cluster of torpid individuals found this day (red arrow denotes the examined female). All these animals were found active the next day.

meloxicam $0.5 \mathrm{mg} \mathrm{kg}^{-1}$. We have previously sterilized the dataloggers with formaldehyde gas and UV exposure for $15 \mathrm{~min}$ and then set them to record temperature hourly. The surgical approach consisted in a small incision $(3 \mathrm{~mm})$ on the abdominal region in their median plane. The device was delicately placed perpendicularly to the body axis, between the layers of the peritoneum. The wound was closed with a stitch using sutures that are self-absorbing, both in the muscular plane and in the skin. Every time, we maintained the animals in the clinic for 2 weeks for recovery after the surgery. No animal was harmed in any of these surgeries. Surgical procedures had a duration of $5 \mathrm{~min}$ per animal and were led by the third author (AE), an expert veterinarian in charge of a center for wildlife recovery (CEREFAS-UACh).

\section{Enclosures and Outdoor Experiment}

We installed four enclosures in San Martin Biological Station, specifically in an area of dense forest and abundant understory, typical of D. gliroides habitat (Fonturbel et al., 2012). Each enclosure is cylindrical ( $\sim \mathrm{m}^{3}$ of volume) and included twigs and plant material mimicking this species' microenvironment. It had a mesh that allows light and ventilation to enter a similar way under the forest canopy, checked with a luxmeter (TASI $21^{\circledR}$ ). We also included one temperature datalogger $\left(\mathrm{HOBO}^{\circledR}\right.$, Onset, United States) set for recording air temperature $\left(T_{\mathrm{A}}\right)$ every $15 \mathrm{~min}$ and located at $1 \mathrm{~m}$ above ground in the shadow. During the outdoor experiment (27 weeks, from April

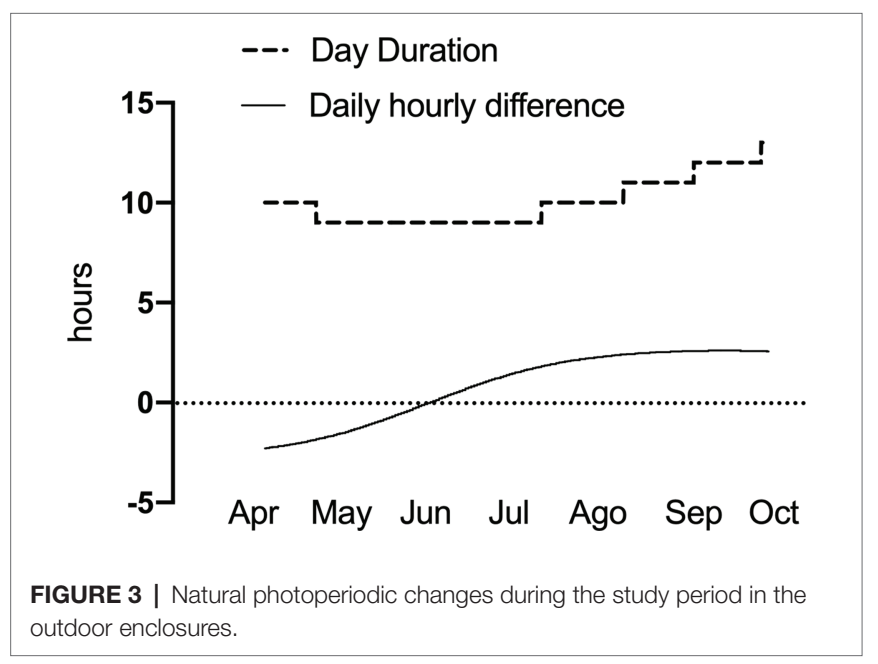

to October 2019), we recorded a mean monsthly $T_{\mathrm{A}}$ ranged from $17.1^{\circ} \mathrm{C}_{\max }$ and $3^{\circ} \mathrm{C}_{\min }$ (the $T_{\mathrm{A}}$ range for one of the enclosures is shown in Results), and the seasonal change in photoperiod was $4.5 \mathrm{~h}$ (Figure 3 ).

Water was provided ad libitum in a plastic plate $(1 \mathrm{~L})$. Each individual was released in one different enclosure, where food was provided daily: two of the animals received "restricted" food (20 $\mathrm{kJ} \mathrm{day}^{-1}$ per animal), and the other two received ad libitum food (100 $\mathrm{kJ} \mathrm{day}^{-1}$ per animal). Food consisted of a mix of cereals, jam, and tuna that provides balanced nutrition 
for this omnivorous species (Contreras et al., 2014). Energy content was determined using a calorimeter (Parr Instruments, IL, United States). This experiment is further referred to as the "outdoor experiment," which aimed to determine how photoperiod, $T_{\mathrm{A}}$, food availability, and body condition induced metabolic reductions. During this experiment, we gently weighed the animals on a weekly basis to determine their body mass $\left(M_{\mathrm{B}}\right)$ and body mass change from the last week. We replaced food plates every day to ensure animals received the constant amounts.

\section{Ramp Experiment}

Given that some of the dataloggers still had operational batteries, we reused them in the 2020 winter, with two newly captured animals in a controlled "ramp experiment" to determine torpor at near-zero $T_{\mathrm{A}}$. We performed the ramp experiment (see similar experiments in Currie et al., 2015), on August 1, 2020, in a Pelt-5 incubator and temperature controller (Sable Systems) set at the mean $T_{\mathrm{A}}$ of the moment (winter, mean $T_{\mathrm{A}}=5.0 \pm 2.1^{\circ} \mathrm{C}$ ) and photoperiod accordingly (10,14, see Figure 3 ). We programmed the incubator for a gradual reduction of $1^{\circ} \mathrm{C}$ per day, passing one day at a stable $T_{\mathrm{A}}$ until $-2.4^{\circ} \mathrm{C}$ (this limit given by the equipment). In a few cases, the cooling system froze, raising the set point's temperature, which did not produce a perfect ramp. Animals did not arouse during these short $T_{\mathrm{A}}$ increments. During the ramp experiment, we offered water ad libitum but removed food. Also, we maintained animals in separated cages within the incubator. After the "cold" ramp, animals remained in the incubator at $15^{\circ} \mathrm{C}$ for 1 week. Then, we assayed the "warm ramp", which consisted of a similar ramping rate as before but increasing temperature from $15^{\circ} \mathrm{C}$ until $28^{\circ} \mathrm{C}$. No animals were harmed during these ramps and were released in the capture site in spring (September 21, 2020) after checking their physiological condition by a trained veterinarian.

\section{Statistical Analyses}

To calculate steady-state torpor temperature (i.e., the critical body temperature where animals start thermoregulating in torpor, $T_{\mathrm{Bmin}}$ ), we performed linear regressions between the thermal differential (i.e., $T_{\mathrm{B}}-T_{\mathrm{A}} ; T_{\mathrm{DIFF}}$ ) and $T_{\mathrm{A}}$ with the data points of the plot where $T_{\text {DIFF }}$ is inversely proportional to $T_{\mathrm{A}}$ during torpor. That is, we amplified each graph and took every point that fell in the bottom-left edge of the figure. To estimate torpor thermoregulation regressions, we predicted the RMR as RMR $=C_{\text {min }}\left(T_{\mathrm{B}}-T_{\mathrm{A}} ;=\right.$ Newton's model for passive cooling, see Rezende and Bacigalupe, 2015); where Cmin is minimum thermal conductance $\left(=3.4848 \mathrm{~J} \mathrm{~g}^{-10} \mathrm{C}^{-1} \mathrm{~h}^{-1}\right.$, see Bozinovic et al., 2004).

The four individuals used for the outdoor experiment produced hourly records of $T_{\mathrm{DIFF}}$ for 25 weeks (=10,533 observations, determined by the data loggers' battery capacity). Then, to determine the combination of variables that trigger torpor, we used $T_{\text {DIFF }}$ as a continuous response variable associated with fixed and random factors. We used $T_{\text {DIFF }}$ because we got non-convergent models when using it as a dichotomic variable (i.e., active or torpor). Each record was associated with the fixed factors: food (low/ high), $T_{\mathrm{A}}\left({ }^{\circ} \mathrm{C}\right)$, photoperiod (daylength in hours), delta photoperiod (difference in daylength from the day before in hours), $M_{\mathrm{B}}(\mathrm{g})$, and $\Delta M_{\mathrm{B}}$ (difference $M_{\mathrm{B}}$ with the previous week). Then, we fitted mixed-effects generalized linear models (GLMM) with a Gaussian error distribution, including individual ID, sampling week, and date as random effects to account for inter-individual and interenclosure variability along with the repeated measures in time (Zuur et al., 2009). We used the Akaike information criteria (AIC) to select the best models and contrast the candidate models' performance. We dropped $M_{\mathrm{B}}$ and delta photoperiod for being redundant with photoperiod and $\Delta M_{\mathrm{B}}$. All combinations of models were tested first, including all possible interactions (not presented). Here, we present the best nine models:

$$
\begin{aligned}
& \rightarrow \text { Model 1: } T_{\mathrm{DIFF}} \sim \text { food }+(1 \mid \mathrm{ID})+(1 \mid \text { Date }) \\
& \rightarrow \text { Model 2: } T_{\mathrm{DIFF}} \sim \text { food }+T_{\mathrm{A}}+(1 \mid \text { week })+(1 \mid \text { ID }) \\
& +(1 \mid \text { Date }) \\
& \rightarrow \text { Model 3: } T_{\text {DIFF }} \sim \text { food }+T_{\mathrm{A}}+\text { photoperiod }+(1 \mid \text { week }) \\
& +(1 \mid \text { ID })+(1 \mid \text { Date }) \\
& \rightarrow \text { Model 4: } T_{\text {DIFF }} \sim \text { food }+T_{\mathrm{A}}+\text { photoperiod }+\Delta \mathrm{M}_{\mathrm{B}}+ \\
& (1 \mid \text { week })+(1 \mid \text { ID })+(1 \mid \text { Date }) \\
& \rightarrow \text { Model 5: } T_{\mathrm{DIFF}} \sim \text { food } \times T_{\mathrm{A}}+(1 \mid \text { week })+(1 \mid \text { ID }) \\
& +(1 \mid \text { Date }) \\
& \rightarrow \text { Model 6: } T_{\text {DIFF }} \sim \text { food } \times \text { photoperiod }+(1 \mid \text { week })+ \\
& (1 \mid \text { ID })+(1 \mid \text { Date }) \\
& \rightarrow \text { Model 7: } T_{\text {DIFF }} \sim T_{\mathrm{A}} \times \text { photoperiod }+(1 \mid \text { week })+ \\
& (1 \mid \text { ID })+(1 \mid \text { Date }) \\
& \rightarrow \text { Model 8: } T_{\mathrm{DIFF}} \sim T_{\mathrm{A}} \times \Delta M_{\mathrm{B}}+(1 \mid \text { week })+(1 \mid \text { ID }) \\
& +(1 \mid \text { Date }) \\
& \rightarrow \text { Model 9: } T_{\mathrm{DIFF}} \sim \text { photoperiod } \times \Delta M_{\mathrm{B}}+(1 \mid \text { week })+ \\
& (1 \mid \text { ID })+(1 \mid \text { Date })
\end{aligned}
$$

The model including all the interactions was discarded since it gave a variance inflation factor $(\mathrm{VIF})=2048$.

We estimated GLMM parameters and their significance using a restricted maximum likelihood approach with a KenwardRoger approximation to estimate degrees of freedom (Halekoh and Hojsgaard, 2014). We performed all analyses using $\mathrm{R}$ version 3.6.0 (Crawley, 2007), with the packages mgcv (Wood, 2011), lme4 (Bates et al., 2013), lmerTest (Kusnetzova et al., 2015), and pbkrtest (Halekoh and Hojsgaard, 2014). We estimated the VIF value from the fitted GLMM models to control for multicollinearity problems. VIF values $>3$ represent a high multicollinearity problem. From the models listed above, only models 7, 8, and 9 resulted in VIF values above 3 .

\section{RESULTS}

We detected a mean of 150 torpor bouts of $13.4 \mathrm{~h}$ of duration in four individuals at the outdoor experiment, with interbout euthermic periods of $13.6 \mathrm{~h}$ (Table 1).

These representative cases are also supported by extensive observations of yearly torpor occurrence in a companion field study (Nespolo et al., 2021). In this study, we recorded a monthly torpor incidence (i.e., the number torpid individuals found in weekly visits, over the total sample of $n=25$ individuals) that increased in winter, but was never zero even in the warmest days of the summer (Figure 4). 
TABLE 1 | Hibernation parameters (mean \pm SE) of monito del monte (Dromiciops gliroides) obtained in this study under natural conditions ( $n=4$; this excludes the ramp experiments).

\begin{tabular}{lccc}
\hline Hibernation paramater & Mean \pm SE & max & min \\
\hline Hibernation duration $(\mathrm{h})$ & $4,053 \pm 30.7$ & 4,132 & 3,999 \\
Number of torpor bouts & $150 \pm 5.1$ & 162 & 139 \\
Mean duration of torpor bouts $(\mathrm{h})$ & $13.4 \pm 0.83$ & 124 & 1 \\
Mean duration of IBE $(\mathrm{h})$ & $13.6 \pm 1.2$ & 116 & 2 \\
Minimal body temperature $\left(T_{\mathrm{B}}{ }^{\circ} \mathrm{C}\right)$ & $4.13 \pm 0.24$ & 4.8 & 3.7
\end{tabular}

Monitos express torpor routinely, sometimes on summer days at $T_{A}=20^{\circ} \mathrm{C}$ (Figure $5 \boldsymbol{A}$ ) and in summer at $\mathrm{CoO} / \mathrm{T}_{\mathrm{A}}\left(15^{\circ} \mathrm{C}\right.$, Figure 5B).

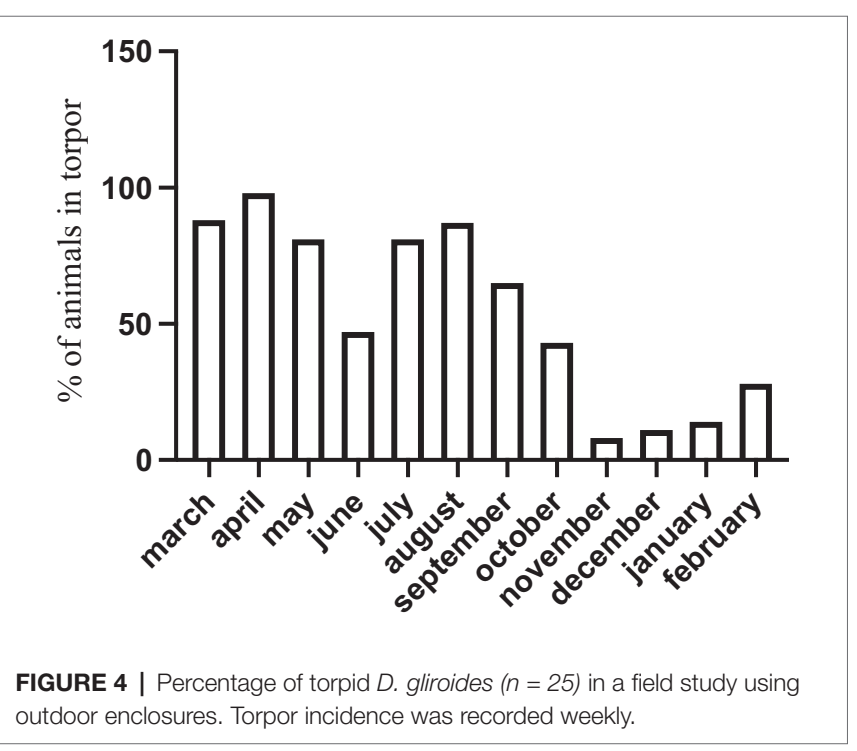

Moreover, monitos enter torpor even during the reproductive period, including females with pups (see Figure 2). However, winter torpor is more frequent, and torpor bouts are longer (Figure 5C), lasting up to $125 \mathrm{~h}$ in some cases (cf. Figure 5D; Table 1).

The variable torpor patterns are also reflected in $T_{\mathrm{DIFF}}$ (Figure 6), from which we calculated the critical torpor temperature $\left(T_{\mathrm{Bmin}}\right)$ below, in which torpid animals start thermoregulating (mean $T_{\mathrm{B} \min }=3.6 \pm 0.9^{\circ} \mathrm{C}, n=6$; Figure 6).

The torpor thermoregulation regression for the pooled sample (six individuals with data loggers) was $\operatorname{RMR}\left(\mathrm{kJh}^{-1}\right)=0.62 \pm 0.2\left(\mathrm{kJh}^{-1}\right)-0.15 \pm 0.03 \times T_{\mathrm{A}}\left(\mathrm{kJh}^{-10} \mathrm{C}^{-1}\right.$; all regressions were significant, with $R^{2}$ values ranging from 0.76 to 0.97). This implies that torpid individuals, once reaching the critical $T_{\mathrm{B}}$ of $3.6^{\circ} \mathrm{C}$, start generating $0.15 \mathrm{~kJ}$ per hour per every $1^{\circ} \mathrm{C}$ reduction. These RMR patterns were quite less variable in the chamber experiment (summarized in Figure 7A), compared with the field (Figure 7B). A representative whole-season pattern of torpor is presented in Figure 7C, as a reference.

The ramp experiments' details, where two monitos were taken to the extreme $T_{\mathrm{A}}$ of -2.4 degrees during two periods of $24 \mathrm{~h}$ and then gradually returned to room temperature with food and water ad libitum, are presented in Figure 8. In these trials, animals entered torpor within the first $12 \mathrm{~h}$ of the experiment, and one individual aroused from torpor when $T_{\mathrm{A}} \mathrm{s}$ felt below zero, it remained euthermic for $24 \mathrm{~h}$, and then it entered torpor again (Figure 8B). The other animal remained in torpor during the whole two periods at sub-zero $T_{\mathrm{A}}$ (Figure 8A). Both individuals maintained their $T_{\mathrm{B}}$ slightly above zero when experiencing sub-freezing temperatures. As indicated before, the first animal had a $T_{\mathrm{Bmin}}$ of 2.4 and the other had a $T_{\mathrm{Bmin}} 0.09^{\circ} \mathrm{C}$ (see Figures $6 \mathrm{E}, \mathbf{F}$ ). Both animals aroused from torpor when $T_{\mathrm{A}}$ was increased above $10^{\circ} \mathrm{C}$, and food was put back in the chamber.

The multi-model analysis indicated that the most important variable explaining torpor occurrence (measured as reductions in $T_{\mathrm{DIFF}}$ ) is a combination of food and photoperiod (Table 2: $\omega \mathrm{AIC}=0.59)$.

Body mass reductions $\left(\Delta M_{\mathrm{B}}\right)$ and photoperiodic changes were dropped from the models, thus not significantly contributing to the observed variation in $T_{\text {DIFF. According }}$ to the obtained coefficients, the most important factor explaining torpor occurrence was photoperiod's main effect, with a coefficient of $9.9 \pm 1.5(p<0.001$, Table 3$)$. The positive value of this coefficient suggests that longer days are associated with higher $T_{\mathrm{DIFF}}$. This term was followed by the interaction between photoperiod and restricted food (coefficient: $-3.2 \pm 1.5, p<0.01$, Table 3 ), whose negative sign suggests that the response to photoperiod was stronger when food was restricted than when provided ad libitum. Food supply alone was not a significant contributor to the observed variation in $T_{\mathrm{DIFF}}(p=0.55$; Table 3$)$.

\section{DISCUSSION}

The comparison of monitos heterothermic patterns with other species suggest a dynamic form of heterothermy that in some respects is similar to daily torpor (i.e., short bouts of less than 24 h, summarized in Ruf and Geiser, 2015). Also, monitos do not restrict their torpor episodes to the cold season (Figure 3); and show a high frequency of arousals during winter (Figure 3C; Table 1). On the other hand, monitos exhibited a torpid $T_{\mathrm{B}}$ that was almost indistinguishable from $T_{\mathrm{A}}$ (Figure 3), with an extreme of $4.13^{\circ} \mathrm{C}$ in the outdoor experiment and $0.08^{\circ} \mathrm{C}$ in the climatic chamber (Figure 5), where animals endured sub-freezing temperatures (Figure 8). These minimum torpid $T_{\mathrm{B}}$ are considerably lower than what is observed in hibernators such as the garden dormouse $\left(=6^{\circ} \mathrm{C}\right.$, from Table 1 in Giroud et al., 2021) and lower than what is reported for most Holarctic and non-Holarctic heterotherms (see Figure 3 in Nowack et al., 2020). Similarly, torpor bout duration reached a maximum of 5.2 days (125 h, Figure 3), which is coincident with the first report of Bozinovic et al. (2004) in the laboratory (=5.0 days). Thus, applying the criteria of Geiser (2020): "hibernators are defined as species that can express multiday torpor of $>2$ days, whereas daily heterotherms are defined as species expressing daily torpor exclusively under all thermal, environmental and nutritional conditions"; monitos would fall into the seasonal torpor category.

We observed torpid monitos at $T_{\mathrm{A}}=25^{\circ} \mathrm{C}$, including females with pups, which suggests these animals express 
A

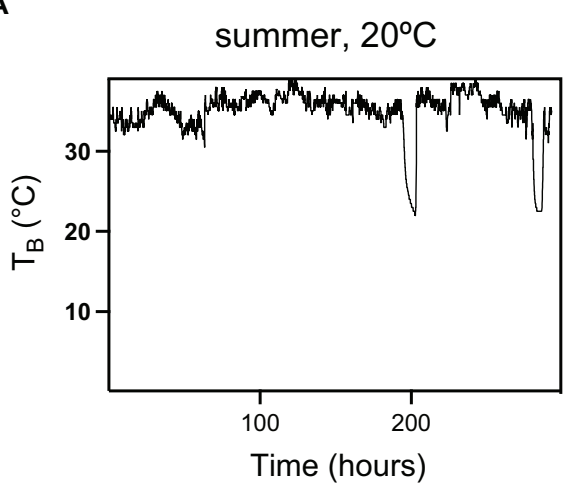

C

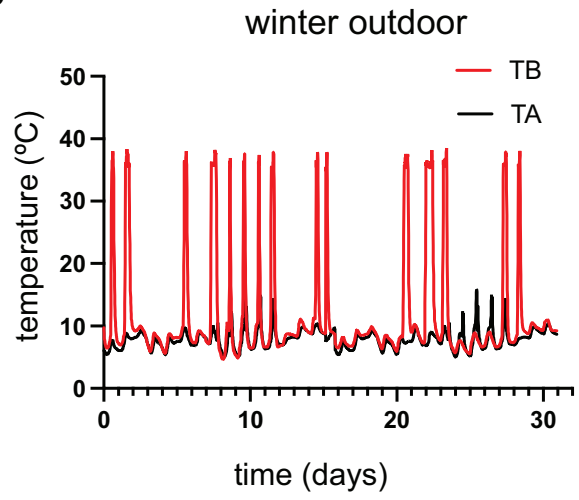

B

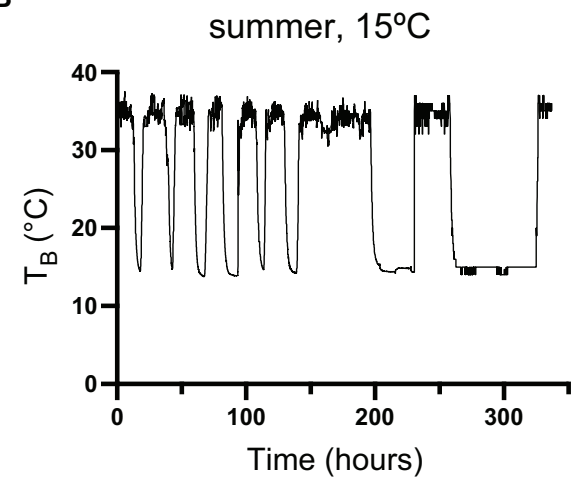

D

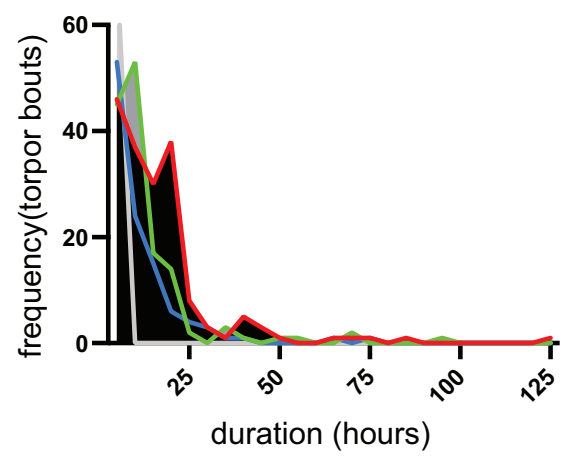

FIGURE 5 | (A) Summer experiments in climatic chambers showing short torpor episodes at $T_{A}=20^{\circ} \mathrm{C}$, (B) summer experiment in climatic chambers showing torpor episodes at $T_{A}=15^{\circ} \mathrm{C}$, (C) a representative record of one heterothermic individual during winter (August), showing a few multiday torpor episodes of several days and frequent periodic arousals, (D) statistics of the outdoor experiment showing a high frequency of short torpor episodes of $10 \mathrm{~h}$, and some long, multiday torpor episodes of 100-125 h (detailed statistics are shown in Table 1; colors represent different individuals).

torpor routinely, irrespective of $T_{\mathrm{A}}$ (see also Figure $5 \mathbf{B}$ ). This is coincident with what was observed in heterothermic birds and mammals in unpredictable environments (e.g., hummingbirds and nig=htjars), which express torpor when incubating and also in mammals of the three orders (i.e., monotremes, marsupials, and placentals), which express torpor during pregnancy and lactation (reviewed in McAllan and Geiser, 2014). Similarly, torpor at room temperatures is known to occur in rodents (Grimpo et al., 2014), bats (Johnson and Lacki, 2014), and primates (Hadj-Moussa and Storey, 2019) as adaptations to seasonally dry habitats. What is intriguing with $D$. gliroides is that it lives in a temperate rainforest characterized by humid and mild temperatures, where the water economy does not seem to be a problem. In fact, evaporative water loss measurements in torpid $D$. gliroides suggest water economy is comparatively poor in this species (Withers et al., 2012). Then, monitos seem to express heterothermia routinely, and regardless of $T_{\mathrm{A}}$.

But also, monitos exhibited endurance to cold. In fact, according to our ramp experiments, monitos reached a $T_{\mathrm{Bmin}}$ of $3.6^{\circ} \mathrm{C}$ (one individual had a $T_{\mathrm{Bmin}}=0.08^{\circ} \mathrm{C}$ ) and endured sub-freezing temperatures during $24 \mathrm{~h}$. These individuals generated $0.15 \mathrm{kJh}^{-1}$, per every Celsius degree reduced (i.e., the negative slope of the torpor thermoregulation regression). In daily heterotherms for instance, these parameters are $T_{\mathrm{Bmin}}=8.3^{\circ} \mathrm{C}$, and the slope of thermoregulation regression $=$ $0.004 \mathrm{kJh}^{-10} \mathrm{C}^{-1}$ for the Rufous-tailed hummingbird (Selasphorus rufus, $M_{\mathrm{B}} \sim 3.3 \mathrm{~g}$; Hiebert, 1990). On the other hand, for fat-tailed dunnarts (Sminthopsis crassicaudata) in winter, $T_{\mathrm{Bmin}}=11^{\circ} \mathrm{C}$ and the thermoregulatory slope is $0.10 \mathrm{kJh}^{-10} \mathrm{C}^{-1}$ (Geiser and Baudinette, 1987). In the Arctic ground squirrel (Urocitellus parryii, $M_{\mathrm{B}} \sim 600 \mathrm{~g}$ ), which is 
A

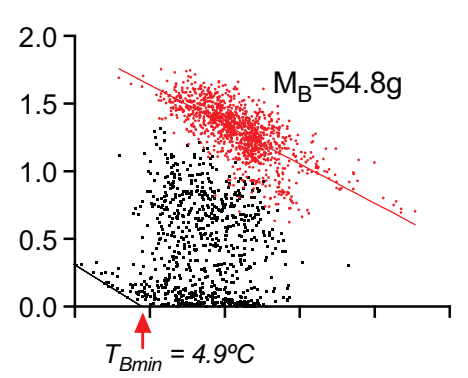

C

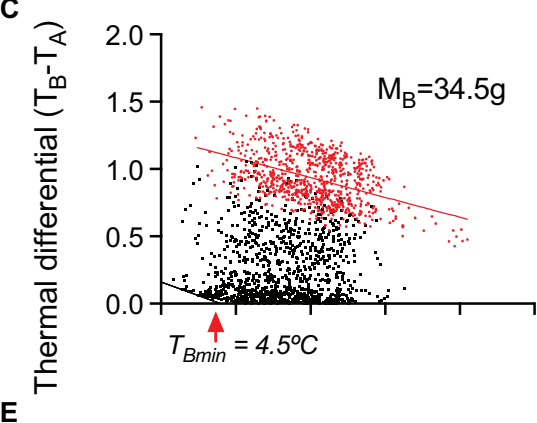

E

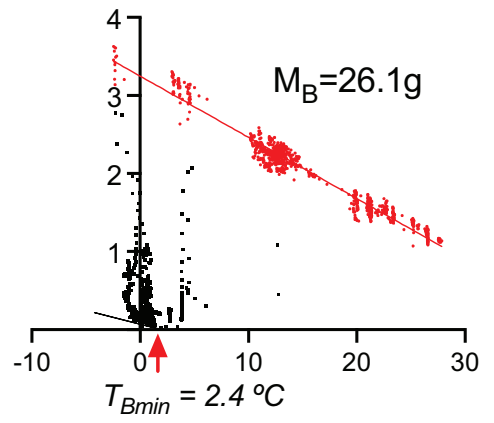

B

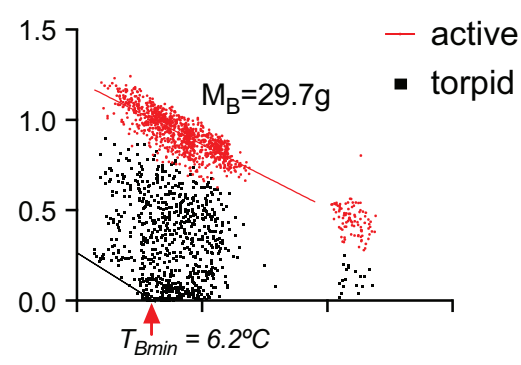

D

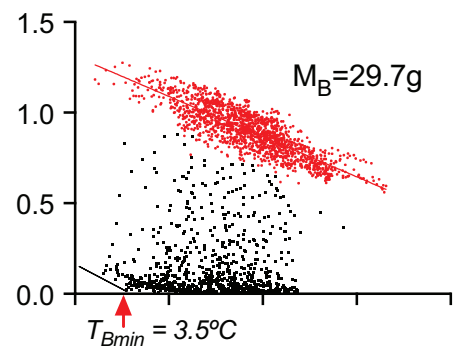

F

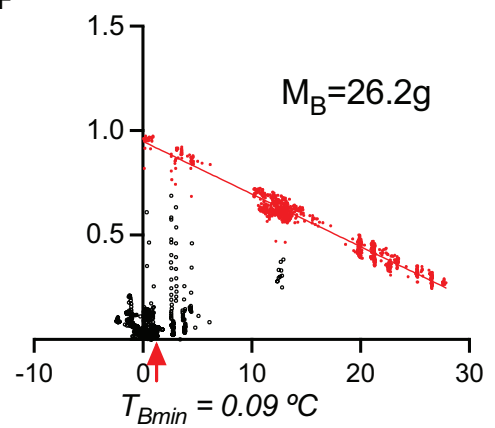

Ambient Temperature $\left({ }^{\circ} \mathrm{C}\right)$

FIGURE 6 | Thermal differential $\left(T_{B}-T_{A}\right)$ in six monitos. The first four animals (A-D) are from the outdoor experiment, and the last two (E,F) were from the ramp experiment, showing torpor at sub-freezing $T_{\mathrm{A}} \mathrm{S}$ (see the details in Figure 8). $T_{\mathrm{Bmin}}$ denotes the temperature at which animals start thermoregulating.

considered an extreme hibernator, the slope of the thermoregulatory regression was $0.17 \mathrm{kJh}^{-10} \mathrm{C}^{-1}$ (transformed to joules from Figure $\mathbf{1}$ at Richter et al., 2015), with $T_{\text {Bmin }}=-3^{\circ} \mathrm{C}$ (Richter et al., 2015). Then, a thermoregulatory slope of $0.15 \mathrm{kJh}^{-10} \mathrm{C}^{-1}$ and $T_{\mathrm{Bmin}}=3.6^{\circ} \mathrm{C}$ seems to be outstanding for a marsupial of temperate regions. Importantly, monitos are found in a relatively broad geographic area, including high Andean locations such as Altos de Lircay (the Northern edge of the distribution of D. gliroides), Futaleufú in Chile, and Parque Nacional Los Alerces in Argentina (latitude $43^{\circ}$ South; Gurovich et al., 2015; Oda et al., 2019), where hibernacula are probably covered by snow during the winter (Honorato et al., 2016). Then, these capabilities are probably important in these high-altitude locations.

Previously, it was suggested that food deprivation combined with cold is important for inducing torpor in monitos (Nespolo et al., 2010), but it was unknown how these daily heterotherm patterns shifts into multiday torpor patterns in winter. Our results suggest that this shift is mainly driven by gradual reductions in the photoperiod, enhanced by reduced food availability (which, in our results, interacted with photoperiod). In general, it is known that experimental food reductions can modify seasonal torpor patterns in hibernators; either generating a shorter hibernation period or inducing shallower torpor episodes (reviewed in Vuarin et al., 2015). This dependence is mechanistically associated with a hypothalamic neuronal circuit stimulated by fasting that lowers the set point for $T_{\mathrm{B}}$ control, a phenomenon known for decades (Heller and Colliver, 1974; Geiser et al., 1990), and recently confirmed at the molecular level in laboratory mice (Hrvatin et al., 2020; Takahashi et al., 2020). In the case of $D$. gliroides, animals can sense the presence of food in the environment and adjust their energy expenditure (by torpor) on a weekly basis (Giroud et al., 2021; Nespolo et al., 2021). This modulation also occurs in other mammalian species of the southern hemisphere, such as African elephant shrews, which show daily heterothermy modulated by 
A

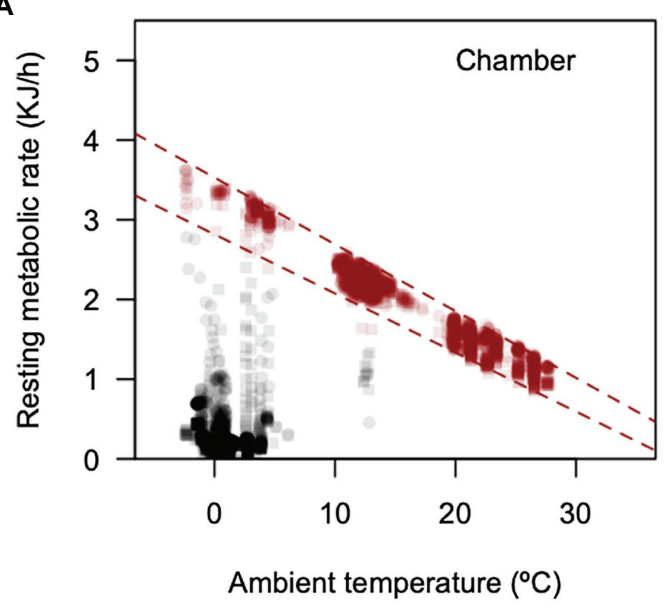

B

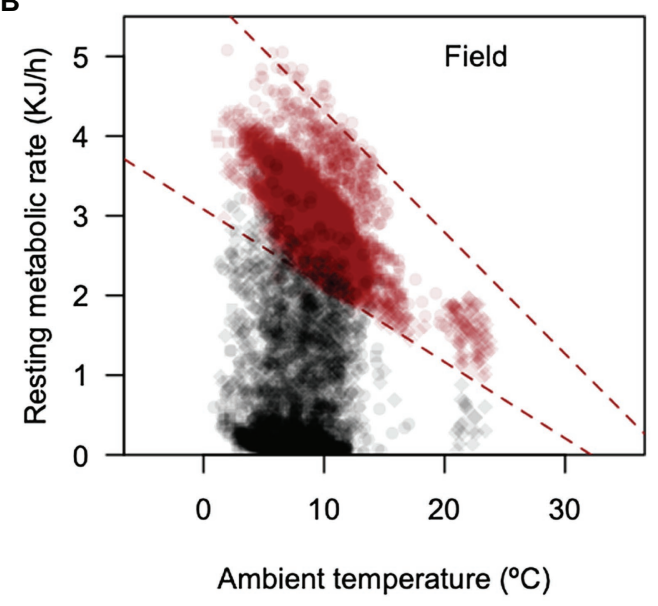

C

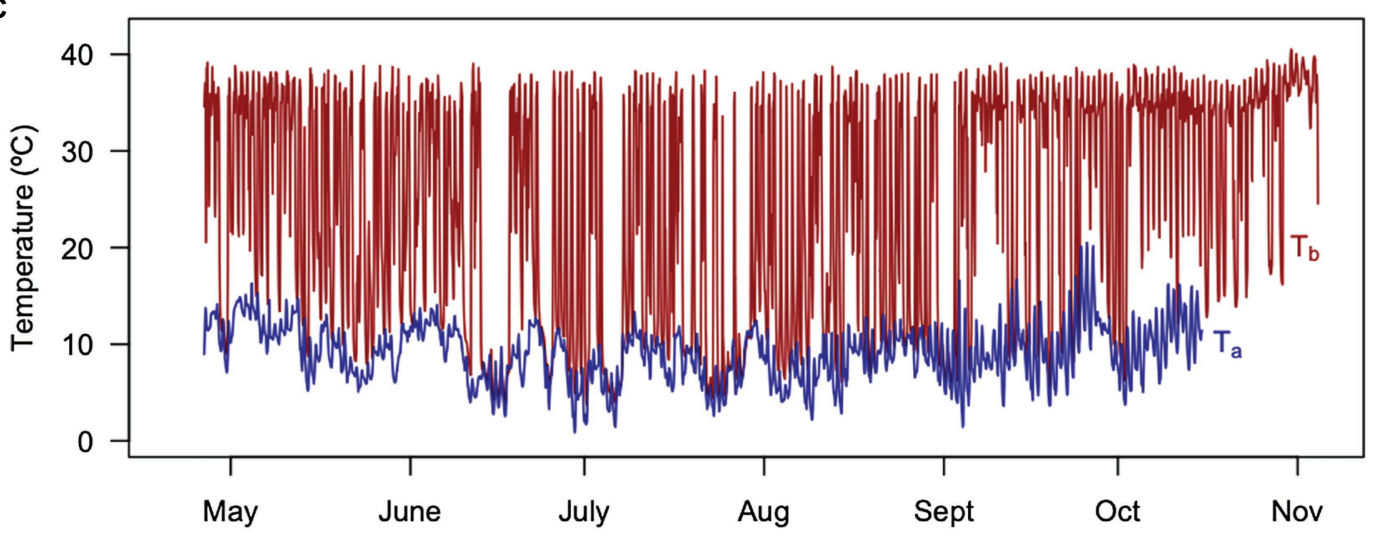

FIGURE 7 | Summaries of calculated RMRs from Figure 5, using Newton's equation for passive cooling: RMR $=C_{\min }\left(T_{\mathrm{B}}-T_{\mathrm{A}}\right)$, where $C_{\min }=3.4848 \mathrm{Jg}^{-1} \mathrm{~h}^{-10} \mathrm{C}^{-1}$ (Bozinovic et al., 2004), comparing the metabolic variability obtained in a climatic chamber (A) ramp experiments and in the field (B) outdoor experiments. (C) Shows the ambient and body temperature of a representative individual during the outdoor experiment.

food, $T_{\mathrm{A}}$, and photoperiod (Mzilikazi and Lovegrove, 2004); in the short-beaked echidnas, which can shift from short torpor to hibernation depending on habitat conditions (Nicol and Andersen, 2007); in the marsupial Antechinus, which intensify torpor use under environmental threats such as food scarcity and fires (Stawski et al., 2016); and in spiny mice, which react with heterothermy in response to storms of floods (reviewed in Nowack et al., 2020). Thus, the opportunistic heterothermic patterns of this Neotropical marsupial then seem to concur with other non-Holarctic species' heterothermic patterns.

Simple bioenergetic models have been successfully applied for calculating hibernation energy requirements using fat storages in the bat Myotis lucifugus (Humphries et al., 2002), for testing contrasting torpor hypotheses in the bat Myotis sodalis (Boyles et al., 2008), as well as for estimating the thermal niche during torpor or euthermia (Landry-Cuerrier et al., 2008). Moreover, previously described patterns of thermoregulation in torpor (Geiser and Baudinette, 1987; Hiebert, 1990; Richter et al., 2015) were carried out through open flow respirometry, a technique that has been crucial for the development of comparative and ecological physiology (e.g., Kleiber, 1932; McNab, 1986; Glazier, 2005; Lighton, 2008), but which at the same time impose important limitations for analyzing free-ranging animals. The results presented here predicting metabolic changes during torpor (see also Humphries et al., 2002; Rezende and Bacigalupe, 2015; Menzies et al., 2020; Wolf et al., 2020) show that bioenergetic models sometimes replace costly laboratory methods and that the use of miniature data loggers in some way allows "animals to perform the experiment."

\section{CONCLUSION}

The Monito del Monte represents the sister lineage of the monophyletic Australidelphia (= Australasian marsupials, Mitchell et al., 2014), exhibiting many of the characteristics of a protoendotherm, and can be considered as a "basoendotherm" (i.e., the endothermic characteristics of Cretaceous and Early Cenozoic mammals, sensu Lovegrove, 2012). According to Lovegrove (2012), the resting, normothermic $T_{\mathrm{B}}$ range of basoendotherms is below $35^{\circ} \mathrm{C}$, with a variation range of $5^{\circ} \mathrm{C}$, which is the case for monitos, 
A
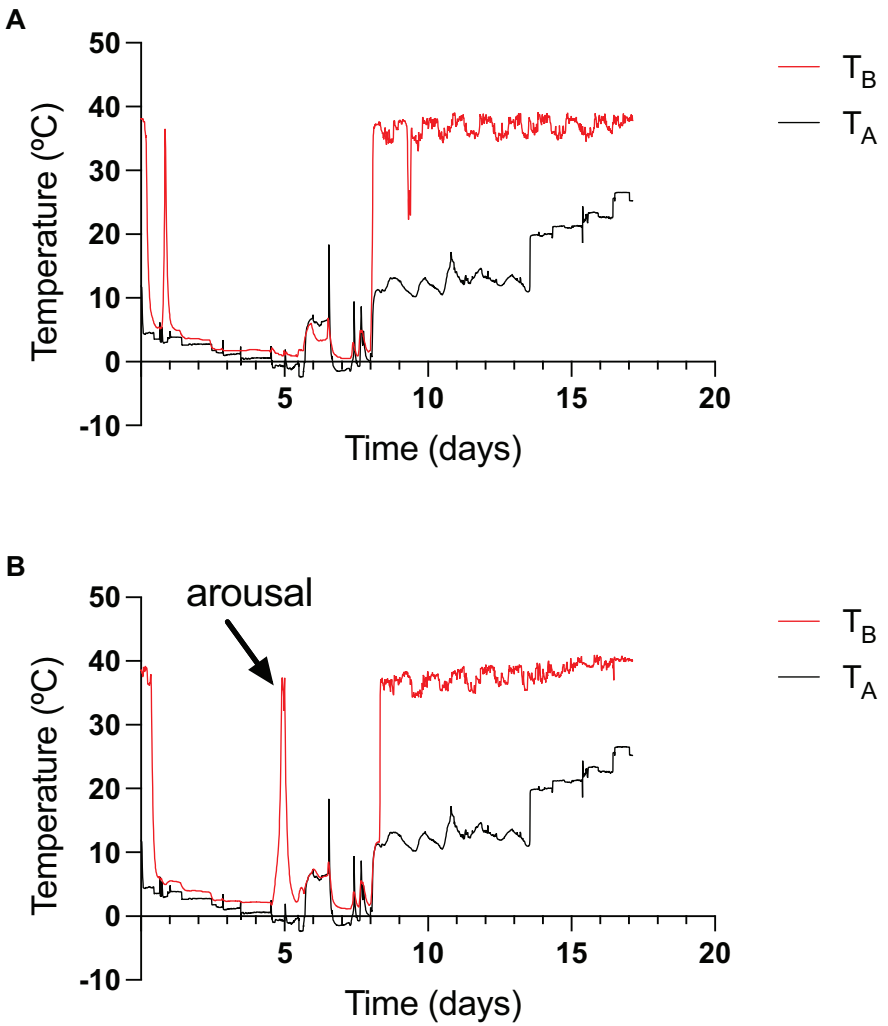

FIGURE 8 | The ramping experiment, where two $D$. gliroides (A,B; without food access), with intraperitoneal data loggers were gradually exposed first to diminishing temperatures from $5^{\circ} \mathrm{C}$ to $-2.4^{\circ} \mathrm{C}$ (rate: $1^{\circ} \mathrm{C}$ day ${ }^{-1}$ ). At day $8, T_{\mathrm{A}}$ was elevated gradually at a similar rate until $28^{\circ} \mathrm{C}$, and food was provided ad libitum. The spikes in $T_{\mathrm{A}}$ are because chamber openings. The elevation of $T_{\mathrm{A}}$ between the sixth and seventh day occurred because of the freezing of the climatic chamber compressor.

TABLE 2 | Multi-model selection results upon nine candidate models based on Akaike information criteria (AICC). Multicollinearity was tested using the maximum value of the variance inflation factor (VIF) for each model.

\begin{tabular}{|c|c|c|c|c|c|c|}
\hline Model & Random & df & $\mathrm{AICc}$ & $\triangle \mathrm{AICc}$ & $\omega \mathbf{A I C}$ & $\max$ VIF \\
\hline$T_{\text {DIFF }} \sim$ food $\times$ photoperiod & $w+I+D$ & 8 & 35666.1 & 0.00 & 0.590 & 1.644 \\
\hline$T_{\text {DIFF }} \sim$ photoperiod $\times \Delta M_{\mathrm{B}}$ & $w+I+D$ & 8 & 35667.7 & 1.59 & 0.266 & 70.905 \\
\hline$T_{\text {DIFF }} \sim$ food $+T_{\mathrm{A}}+$ photoperiod $+\Delta M_{\mathrm{B}}$ & $w+I+D$ & 9 & 35674.6 & 8.55 & 0.008 & 1.043 \\
\hline$T_{\text {DIFF }} \sim T_{A} \times \Delta M_{B}$ & $w+I+D$ & 8 & 35700.1 & 34.05 & $<0.001$ & 5.717 \\
\hline$T_{\text {DIFF }} \sim$ food $+T_{\mathrm{A}}+$ photoperiod & $w+I+D$ & 8 & 35702.9 & 36.85 & $<0.001$ & 1.039 \\
\hline$T_{\text {DIFF }} \sim$ food & $1+D$ & 5 & 36759.5 & 1093.40 & $<0.001$ & 1.000 \\
\hline
\end{tabular}

$R M R$, resting metabolic rate; food = calorie restriction treatment (restricted or ad libitum), photoperiod = photoperiod (number of light hours per day), $\Delta M_{B}=$ weekly change in body mass, $T_{A}=$ ambient temperature. Random factors were week (W), ID (I), and date (D).

TABLE 3 | Estimates of the fixed effects from the mixed-effects generalized linear models (the best model chosen after multi-model selection, see Table 2) used to assess the determinant factors on thermal differential ( $\left.T_{\mathrm{DIFF}}\right)$.

\begin{tabular}{lrrr}
\hline Fixed effects & Coefficient \pm SE & \multicolumn{1}{c}{$\boldsymbol{t}$} & $\boldsymbol{P}$ \\
\hline Intercept & $-1.352 \pm 0.767$ & -1.762 & 0.090 \\
Food (restricted) & $0.410 \pm 0.603$ & 0.679 & 0.545 \\
Photoperiod & $9.935 \pm 1.493$ & 6.653 & $<0.001$ \\
Food (res) $\times$ Photoperiod & $-3.237 \pm 0.608$ & -5.320 & $<0.001$ \\
\hline
\end{tabular}

Reference levels for categorical predictors are in parenthesis. Random effects were: week, date, and individual ID (non-significant). which can have $10^{\circ} \mathrm{C}$ of $T_{\mathrm{B}}$ variation in euthermia (Cortes et al., 2009; Nespolo et al., 2010). Given that homeothermy in mammals could have evolved in hot climates through an ancestral heterothermal state (Nowack et al., 2020), early mammals may have relied primarily on passive body temperature regulation with the ability to upregulate shortor long-term metabolism when needed. This is consistent with the thermal niche expansion model, which poses that the evolution of endothermy in mammals occurred via the shift from nocturnality to diurnally (see Crompton et al., 1978; reviewed in Hayes and Garland, 1995). 
Then, monitos are excellent models to study the evolution of endothermy, as they represent the living legacy of ancestral basoendotherm-heterotherms.

\section{DATA AVAILABILITY STATEMENT}

The raw data supporting the conclusions of this article will be made available by the authors, without undue reservation.

\section{ETHICS STATEMENT}

The animal study was reviewed and approved by the Chilean Agriculture and Livestock Bureau (SAG; permits No $4371 / 2019$ and 3393/2019), and by the Bioethics Committee of the Austral University of Chile (resolution 313/2018 annex 2019).

\section{REFERENCES}

Bates, B., Maechler, M., and Bolker, B. (2013). lme4: linear mixed-effects models using S4 classes. R package Version 0.999375-39. Available at: http://CRAN.Rproject.org/package $=$ lme 4

Boyles, J. G., Storm, J. J., and Brack, V. (2008). Thermal benefits of clustering during hibernation: a field test of competing hypotheses on Myotis sodalis. Funct. Ecol. 22, 632-636. doi: 10.1111/j.1365-2435.2008.01423.x

Bozinovic, F., Contreras, L., Rosenmann, M., and Torres-Mura, J. C. (1985). Bioenergética de myotis chiloensis (quiroptera: vespertilionidae). Rev. Chil. Hist. Nat. 58, 39-45.

Bozinovic, F., and Marquet, P. A. (1991). Energetics and torpor in the Atacama desert-dwelling rodent Phyllotis darwini rupestris. J. Mammal. 72, 734-738. doi: $10.2307 / 1381835$

Bozinovic, F., Munoz, J. L. P., Naya, D. E., and Cruz-Neto, A. P. (2007). Adjusting energy expenditures to energy supply: food availability regulates torpor use and organ size in the Chilean mouse-opossum Thylamys elegans. J. Comp. Physiol. B 177, 393-400. doi: 10.1007/s00360-006-0137-0

Bozinovic, F., Ruiz, G., and Rosenmann, M. (2004). Energetics and torpor of a South American "living fossil", the microbiotheriid Dromiciops gliroides, J. Comp. Physiol. B 174, 293-297. doi: 10.1007/s00360-004-0414-8

Carpenter, F. L. (1974). Torpor in an Andean hummingbird: its ecological significance. Science 183, 544-547. doi: 10.1126/science.183.4124.545

Contreras, C., Franco, M., Place, N. J., and Nespolo, R. F. (2014). The effects of poly-unsaturated fatty acids on the physiology of hibernation in a South American marsupial, Dromiciops gliroides. Comp. Biochem. Physiol. A Mol. Integr. Physiol. 177, 62-69. doi: 10.1016/j.cbpa.2014.07.004

Cortes, P. A., Franco, M., Moreno-Gomez, F. N., Barrientos, K., and Nespolo, R. F. (2014). Thermoregulatory capacities and torpor in the South American marsupial, Dromiciops gliroides. J. Therm. Biol. 45, 1-8. doi: 10.1016/j. jtherbio.2014.07.003

Cortes, P., Quijano, S. A., and Nespolo, R. F. (2009). Bioenergetics and interindividual variation in physiological capacities in a relict mammal - the monito del monte (Dromiciops gliroides). J. Exp. Biol. 212, 297-304. doi: $10.1242 /$ jeb.021212

Crawley, M. J. (2007). A Language and Environment for Statistical Computing: The $R$ book. New York: Wiley.

Crompton, A. W., Taylor, C. R., and Jagger, J. A. (1978). Evolution of homeothermy in mammals. Nature 272, 333-336. doi: 10.1038/272333a0

Currie, S. E., Noy, K., and Geiser, F. (2015). Passive rewarming from torpor in hibernating bats: minimizing metabolic costs and cardiac demands. Am. J. Phys. Regul. Integr. Comp. Phys. 308, R34-R41. doi: 10.1152/ajpregu.00341.2014

Fonturbel, F. E., Franco, M., Rodriguez-Cabal, M. A., Rivarola, M. D., and Amico, G. C. (2012). Ecological consistency across space: a synthesis of

\section{AUTHOR CONTRIBUTIONS}

$\mathrm{RN}$ conceived the study, designed the methodology, and wrote the first draft of the manuscript. $\mathrm{CM}$ and $\mathrm{AE}$ contributed to the field and laboratory work, and manuscript editions. ER, FB, and FF contributed with the statistical analyses and manuscript editions. All authors contributed to the article and approved the submitted version.

\section{FUNDING}

This work was funded by the FONDECYT grant 1180917 to RN and ANID/PIA/BASAL FB0002 to FB, RN, and ER.

\section{ACKNOWLEDGMENTS}

We thank Luis Castañeda for providing us one climatic chamber for the ramp experiments.

the ecological aspects of Dromiciops gliroides in Argentina and Chile. Naturwissenschaften 99, 873-881. doi: 10.1007/s00114-012-0969-2

Franco, M., Contreras, C., Place, N. J., Bozinovic, F., and Nespolo, R. F. (2017). Leptin levels, seasonality and thermal acclimation in the Microbiotherid marsupial Dromiciops gliroides: does photoperiod play a role? Comp. Biochem. Physiol. A Mol. Integr. Physiol. 203, 233-240. doi: 10.1016/j.cbpa.2016.09.025

Gannon, W. L., Sikes, R. S., and Comm, A. C. U. (2007). Guidelines of the American Society of Mammalogists for the use of wild mammals in research. J. Mammal. 88, 809-823. doi: 10.1644/06-MAMM-F-185R1.1

Geiser, F. (2020). Seasonal expression of avian and mammalian daily torpor and hibernation: not a simple summer-winter affair. Front. Physiol. 11:436. doi: 10.3389 /fphys.2020.00436

Geiser, F., and Baudinette, R. V. (1987). Seasonality of torpor and thermoregulation in 3 dasyurid marsupials. J. Comp. Physiol. B 157, 335-344. doi: 10.1007/ BF00693360

Geiser, F., and Heldmaier, G. (1995). The impact of dietary fats, photoperiod, temperature and season on morphological variables, torpor patterns, and brown adipose tissue fatty acid composition of hamsters, Phodopus sungorus. J. Comp. Physiol. B 165, 406-415. doi: 10.1007/BF00387311

Geiser, F., Hiebert, S., and Kenagy, G. J. (1990). Torpor bout duration during the hibernation season of 2 sciurid rodents - interrelations with temperature and metabolism. Physiol. Zool. 63, 489-503. doi: 10.1086/ physzool.63.3.30156224

Geiser, F., and Körtner, G. (2010). Hibernation and daily torpor in Australian mammals. Aust. Zool. 35, 204-215. doi: 10.7882/AZ.2010.009

Geiser, F., and Martin, G. M. (2013). Torpor in the patagonian opossum (Lestodelphys halli): implications for the evolution of daily torpor and hibernation. Naturwissenschaften 100, 975-981. doi: 10.1007/s00114-013-1098-2

Geiser, F., and Ruf, T. (1995). Hibernation versus daily torpor in mammals and birds: physiological variables and classification of torpor patterns. Physiol. Biochem. Zool. 68, 935-966. doi: 10.1086/physzool.68.6.30163788

Giroud, S., Habold, C., Nespolo, R. F., Mejias, C., Terrien, J., Logan, S. M., et al. (2021). The torpid state: recent advances in metabolic adaptations and protective mechanisms. Front. Physiol. 11:623665. doi: 10.3389/ fphys.2020.623665

Glazier, D. S. (2005). Beyond the "3/4-power law": variation in the intra- and interspecific scaling of metabolic rate in animals. Biol. Rev. 80, 611-662. doi: $10.1017 / S 1464793105006834$

Goin, F. J., and Abello, M. A. (2013). South American metatherians from the begining of the neogene (early miocene, colhuehuapian land-mammal age) Microbiotheria and polydolopimorphia. Ameghiniana 50, 51-78. doi: 10.5710/ AMGH.9.11.2012.570

Goin, F. J., Woodburne, M. O., Zimicz, N., Martin, G. M., and Chornogubsky, L. (2016). A Brief History of South American Metatherians. New York: Springer. 
Grimpo, K., Kutschke, M., Kastl, A., Meyer, C. W., Heldmaier, G., Exner, C., et al. (2014). Metabolic depression during warm torpor in the golden spiny mouse (Acomys russatus) does not affect mitochondrial respiration and hydrogen peroxide release. Comp. Biochem. Physiol. A Mol. Integr. Physiol. 167, 7-14. doi: 10.1016/j.cbpa.2013.09.002

Gurovich, Y., Stannard, H. J., and Old, J. M. (2015). The presence of the marsupial Dromiciops gliroides in parque nacional los alerces, Chubut, Southern Argentina, after the synchronous maturation and flowering of native bamboo and subsequent rodent irruption. Rev. Chil. Hist. Nat. 88:17. doi: 10.1186/ s40693-015-0047-1

Hadj-Moussa, H., and Storey, K. B. (2019). Bringing nature back: using hibernation to reboot organ preservation. FEBS J. 286, 1094-1100. doi: $10.1111 /$ febs. 14683

Hainsworth, F. R., and Wolf, L. L. (1970). Regulation of oxygen consumption and body temperature during torpor in a hummingbird, Eulampis jugularis. Science 168, 368-369. doi: 10.1126/science.168.3929.368

Halekoh, U., and Hojsgaard, S. (2014). Kenward-roger approximation and parametric bootstrap methods for tests in linear mixed models - the $\mathrm{R}$ package pbkrtest. J. Stat. Softw. 59, 1-32.

Hayes, J. P., and Garland, T. (1995). The evolution of endothermy: testing the aerobic capacity model. Evolution 49, 836-847. doi: 10.1111/j.1558-5646.1995. tb02320.x

Heldmaier, G., Ortmann, S., and Elvert, R. (2004). Natural hypometabolism during hibernation and daily torpor in mammals. Respir. Physiol. Neurobiol. 141, 317-329. doi: 10.1016/j.resp.2004.03.014

Heller, H. C., and Colliver, G. W. (1974). CNS regulation of body temperature during hibernation. Am. J. Phys. 227, 583-589. doi: 10.1152/ ajplegacy.1974.227.3.583

Hershkovitz, P. (1999). Dromiciops gliroides Thomas, 1894, last of the Microbiotheria (Marsupialia), with a review of the family Microbiotheridae. Fieldana 93, $1-60$.

Hiebert, S. M. (1990). Energy costs and temporal organization of torpor in the rufous hummingbird (Selasphorus rufus). Physiol. Zool. 63, 1082-1097. doi: 10.1086/physzool.63.6.30152634

Honorato, M. T., Altamirano, T. A., Ibarra, J. T., De La Maza, M., Bonacic, C., and Martin, K. (2016). Composition and preferences regarding nest materials by cavity-nesting vertebrates in the Andean temperate forest of Chile. Bosque 37, 485-492. doi: 10.4067/S0717-92002016000300005

Hrvatin, S., Sun, S., Wilcox, O. F., Yao, H., Lavin-Peter, A. J., Cicconet, M., et al. (2020). Neurons that regulate mouse torpor. Nature 583, 115-121. doi: $10.1038 / \mathrm{s} 41586-020-2387-5$

Humphries, M. M., Thomas, D. W., and Speakman, J. R. (2002). Climatemediated energetic constraints on the distribution of hibernating mammals. Nature 418, 313-316. doi: 10.1038/nature00828

Johnson, J. S., and Lacki, M. J. (2014). Effects of reproductive condition, roost microclimate, and weather patterns on summer torpor use by a vespertilionid bat. Ecol. Evol. 4, 157-166. doi: 10.1002/ece3.913

Kleiber, M. (1932). Body size and metabolism. Hilgardia 6, 315-353. doi: 10.3733/hilg.v06n11p315

Kusnetzova, A., Brockhoff, P. B., and Haubo, R. (2015). lmerTest: test in linear mixed effects models. R package version 2.0-25. Available at: http://CRAN.Rproject.org/package=lmerTest

Landry-Cuerrier, M., Munro, D., Thomas, D. W., and Humphries, M. M. (2008). Climate and resource determinants of fundamental and realized metabolic niches of hibernating chipmunks. Ecology 89, 3306-3316. doi: 10.1890/08-0121.1

Lighton, J. R. B. (2008). Measuring Metabolic Rates. New York: Oxford University Press.

Lovegrove, B. G. (2012). The evolution of endothermy in cenozoic mammals: a plesiomorphic-apomorphic continuum. Biol. Rev. 87, 128-162. doi: 10.1111/j. 1469-185X.2011.00188.x

Lovegrove, B. G., and Genin, F. (2008). Torpor and hibernation in a basal placental mammal, the lesser hedgehog tenrec Echinops telfairi. J. Comp. Physiol. B 178, 691-698. doi: 10.1007/s00360-008-0257-9

Lovegrove, B. G., Raman, J., and Perrin, M. R. (2001). Heterothermy in elephant shrews, Elephantulus spp. (Macroscelidea): daily torpor or hibernation? J. Comp. Physiol. B 171, 1-10. doi: 10.1007/s003600000139

McAllan, B. M., and Geiser, F. (2014). Torpor during reproduction in mammals and birds: dealing with an energetic conundrum. Integr. Comp. Biol. 54, 516-532. doi: 10.1093/icb/icu093
McNab, B. K. (1986). The influence of food habits on the energetics of eutherian mammals. Ecol. Monogr. 56, 1-19. doi: 10.2307/2937268

Mejias, C., Castro-Pastene, C. A., Carrasco, H., Quintero-Galvis, J. F., Soto-Gamboa, M., Bozinovic, F., et al. (2021). Natural history of the relict marsupial monito del monte at the most extreme altitudinal and latitudinal location. Ecosphere (in press).

Menzies, A. K., Studd, E. K., Majchrzak, Y. N., Peers, M. J. L., Boutin, S., Ben, D., et al. (2020). Body temperature, heart rate, and activity patterns of two boreal homeotherms in winter: homeostasis, allostasis, and ecological coexistence. Funct. Ecol. 34, 2292-2301. doi: 10.1111/1365-2435.13640

Mitchell, K. J., Pratt, R. C., Watson, L. N., Gibb, G. C., Llamas, B., Kasper, M., et al. (2014). Molecular phylogeny, biogeography, and habitat preference evolution of marsupials. Mol. Biol. Evol. 31, 2322-2330. doi: 10.1093/molbev/msu176

Muñoz-Pedreros, A., Lang, B. K., Bretos, M., and Meserve, P. L. (2005). Reproduction and development of Dromiciops gliroides (Marsupialia: Microbiotheridae) in temperate rainforests of southern Chile. Gayana 69, 225-233.

Mzilikazi, N., and Lovegrove, B. G. (2004). Daily torpor in free-ranging rock elephant shrews, Elephantulus myurus: a year-long study. Physiol. Biochem. Zool. 77, 285-296. doi: 10.1086/381470

Nespolo, R. F., Fontúrbel, F. E., Mejias, C., Contreras, R., Gutierrez, P., Oda, E., et al. (2021). A mesocosm experiment in ecological physiology: adaptive modulation of energy budget in a hibernating marsupial under chronic caloric restriction. bioRxiv [Preprint]. doi: 10.1101/2020.06.05.136028

Nespolo, R. F., Verdugo, C., Cortes, P. A., and Bacigalupe, L. D. (2010). Bioenergetics of torpor in the microbiotherid marsupial, monito del monte (Dromiciops gliroides): the role of temperature and food availability. J. Comp. Physiol. B 180, 767-773. doi: 10.1007/s00360-010-0449-y

Nicol, S. C., and Andersen, N. A. (2007). Cooling rates and body temperature regulation of hibernating echidnas (Tachyglossus aculeatus). J. Exp. Biol. 210, 586-592. doi: 10.1242/jeb.02701

Nilsson, M. A., Churakov, G., Sommer, M., Van Tran, N., Zemann, A., Brosius, J., et al. (2010). Tracking marsupial evolution using archaic genomic retroposon insertions. PLoS Biol. 8:e1000436. doi: 10.1371/journal.pbio.1000436

Nowack, J., Levesque, D. L., Reher, S., and Dausmann, K. H. (2020). Variable climates lead to varying phenotypes: "weird" mammalian torpor and lessons from non-Holarctic species. Front. Ecol. Evol. 8:60. doi: 10.3389/fevo.2020.00060

Oda, E., Rodriguez-Gomez, G. B., Fonturbel, F. E., Soto-Gamboa, M., and Nespolo, R. F. (2019). Southernmost records of Dromiciops gliroides: extending its distribution beyond the Valdivian rainforest. Gayana 83, 145-149. doi: 10.4067/S0717-65382019000200145

Ortmann, S., Heldmaier, G., Schmid, J., and Ganzhorn, J. U. (1997). Spontaneous daily torpor in malagasy mouse lemurs. Naturwissenschaften 84, 28-32. doi: $10.1007 / \mathrm{s} 001140050344$

Rezende, E. L., and Bacigalupe, L. D. (2015). Thermoregulation in endotherms: physiological principles and ecological consequences. J. Comp. Physiol. B 185, 709-727. doi: 10.1007/s00360-015-0909-5

Richter, M. M., Williams, C. T., Lee, T. N., Toien, O., Florant, G. L., Barnes, B. M., et al. (2015). Thermogenic capacity at subzero temperatures: how low can a hibernator go? Physiol. Biochem. Zool. 88, 81-89. doi: 10.1086/679591

Ruf, T., and Geiser, F. (2015). Daily torpor and hibernation in birds and mammals. Biol. Rev. 90, 891-926. doi: 10.1111/brv.12137

Schmid, J., and Ganzhorn, J. U. (2009). Optional strategies for reduced metabolism in gray mouse lemurs. Naturwissenschaften 96, 737-741. doi: 10.1007/ s00114-009-0523-z

Schmidt-Nielsen, K. (1979). Animal Physiology: Adaptation and Environment. New York: Cambridge University Press.

Sikes, R. S., Gannon, W. L., and American Society of Mammalogists (2011). Guidelines of the American Society of Mammalogists for the use of wild mammals in research. J. Mammal. 92, 235-253. doi: 10.1644/10-MAMM-F-355.1

Stawski, C., Kortner, G., Nowack, J., and Geiser, F. (2016). Phenotypic plasticity of post-fire activity and thermal biology of a free-ranging small mammal. Physiol. Behav. 159, 104-111. doi: 10.1016/j.physbeh.2016.03.009

Takahashi, T. M., Sunagawa, G. A., Soya, S., Abe, M., Sakurai, K., Ishikawa, K., et al. (2020). A discrete neuronal circuit induces a hibernation-lile state in rodents. Nature 583, 109-114. doi: 10.1038/s41586-020-2163-6

Uribe, S. V., Chiappe, R. G., and Estades, C. F. (2017). Persistence of Dromiciops gliroides in landscapes dominated by Pinus radiata plantations. Rev. Chil. Hist. Nat. 90:2. doi: 10.1186/s40693-017-0065-2 
Vuarin, P., Dammhahn, M., Kappeler, P. M., and Henry, P. Y. (2015). When to initiate torpor use? Food availability times the transition to winter phenotype in a tropical heterotherm. Oecologia 179, 43-53. doi: 10.1007/s00442-015-3328-0

Withers, P. C., Cooper, C. E., and Nespolo, R. F. (2012). Evaporative water loss, relative water economy and evaporative partitioning of a heterothermic marsupial, the monito del monte (Dromiciops gliroides). J. Exp. Biol. 215, 2806-2813. doi: 10.1242/jeb.070433

Wolf, B. O., McKechnie, A. E., Schmitt, C. J., Czenze, Z. J., Johnston, A. B., and Witt, C. C. (2020). Extreme and variable torpor among high-elevation andean hummingbird species. Biol. Lett. 16:20200428. doi: 10.1098/ rsbl.2020.0428

Wood, S. N. (2011). Fast stable restricted maximum likelihood and marginal likelihood estimation of semiparametric generalized linear models. J. $R$. Stat. Soc. Ser. B Stat. Methodol. 73, 3-36. doi: 10.1111/j.1467-9868.2010.00749.x
Zuur, A., Ieno, E. N., Walker, N., Saveliev, A. A., and Smith, G. M. (2009). Mixed Effects Models and Extensions in Ecology With R. New York: Springer.

Conflict of Interest: The authors declare that the research was conducted in the absence of any commercial or financial relationships that could be construed as a potential conflict of interest.

Copyright (C) 2021 Nespolo, Mejías, Espinoza, Quintero-Galvis, Rezende, Fontúrbel and Bozinovic. This is an open-access article distributed under the terms of the Creative Commons Attribution License (CC BY). The use, distribution or reproduction in other forums is permitted, provided the original author(s) and the copyright owner(s) are credited and that the original publication in this journal is cited, in accordance with accepted academic practice. No use, distribution or reproduction is permitted which does not comply with these terms. 